\title{
Comparative Study on The Analysis Results of Multi-Storeyed Commercial Building (G+12) by Using Staad.Pro and ETABS
}

\author{
K. Harshavardhana Reddy ${ }^{1}$, D. Mohammed Rafi ${ }^{2}$, Dr. C. Ramachandrudu ${ }^{3}$
}

${ }^{*}$ M.Tech Scholar, St.Mark Educational Institution Society Group of Institutions, Anantapur, Andhra Pradesh, India

"2Assistant Professor, "3Professor, Civil Engineering Department, Chiranjeevi Reddy Institute of Engineering \& Technology, Anantapur, Andhra Pradesh, India

\section{ABSTRACT}

Structural Analysis is a branch which involves in the determination of behavior of structures in order to predict the responses of real structures such as buildings, bridges, trusses etc. Under the improvement of expected loading \& external environment during the service life of structure. The results of analysis are used to verify the structure fitness for use. Computer software's are also being used for the calculation of forces, bending moment, stress, strain \& deformation or deflection for a complex structural system. The principle objective of this project is "The Comparative Study on Analysis Results of Multistoreyed Commercial Building (G+12) by STAAD.Pro and ETABS". STAAD.Pro is one of the leading software's for the design of structures. In this project we had analyzed the G+12 building for finding the shear forces, bending moments, deflections details for the structural components of building (such as Beams, Columns \& Slabs) to develop the economic design. ETABS is also leading design software in present days used by many structural designers. Here I have also analyzed the same structure using ETABS software for the design. Finally I made an attempt to define the economical section of G+12 multistoried building using STAAD.Pro and ETABS comparatively.

Keywords : Bending Moment, Deformation, Deflection, Etabs, Staad Pro, Stress, Strain, Slab

\section{INTRODUCTION}

An RCC framed structure is basically an assembly of slabs, beams, columns and foundation interconnected to each other as a unit. The load transfer, in such a structure takes place from the slabs to the beams, from the beams to the columns and then to the lower columns and finally to the foundation which in turn transfers it to the soil. The floor area of a R.C.C framed structure building is 10 to 12 percent more than that of a load bearing walled building. Monolithic construction is possible with R.C.C framed structures and they can resist vibrations, earthquakes and shocks more effectively than load bearing walled buildings. Speed of construction for
RCC framed structures is more rapid. Reinforced concrete is a composite material in which concrete's relatively low tensile strength and ductility are counteracted by the inclusion of reinforcement having higher tensile strength and ductility. The reinforcement is usually embedded passively in the concrete before the concrete sets.

Exact seismic analysis of the structure is highly complex and to tackle this complexity, number of researches has been done with an aim to counter the complex dynamic effect of seismic induced forces in structures. This re-examination and continuous effort has resulted ins everal revisions of Indian Standard: 1893 (1962, 
1966, 1970, 1975, 1984 and 2002) code of practice on —Criteria for earthquake resistant design of structures by the Bureau of Indian Standards (BIS), New Delhi. Many of the analysis techniques are being used in design and incorporated in codes of practices of many countries. However, since in the present study our main focus is on the IS a codal provision, the method of analysis described in IS 1893 (Part 1): 2002 are presented in this chapter.

\section{DESIGNOLATERALOFORCE}

The procedure recommended for the determination of lateral force in IS: 1893-2002(Part 1) performing are based on the approximation that effects of yielding can be accounted for by linear analysis of the building using design spectrum. This analysis is carried out by either equivalent lateral force procedure or dynamic analysis procedure given in the clause 7.8 of IS: 1893-2002 (Part 1). The main difference between the two procedures lies in the magnitude and distribution of lateral forces over the height of the building. In the dynamic analysis procedure, the lateral forces are based on properties of the natural vibration modes of the building which are determined by distribution of mass and stiffness over the height. In the equivalent lateral force procedure the magnitude of forces is based on an estimation of the fundamental period and on the distribution of forces as given by a simple empirical formula that is appropriate only for regular buildings. The following sections will discuss in detail the above mentioned procedures of seismic analysis.

\subsection{EQUIVALENT LATERAL FORCE METHOD}

The total design lateral force or design base shear along any principal direction is given in terms of design horizontal seismic coefficient and seismic weight of the structure. Design horizontal seismic coefficient depends on the zone factor of the site, importance of the structure, response reduction factor of the lateral load resisting elements and the fundamental period of the structure. The procedure generally used for the equivalent static analysis is explained below:

(i) Determination of fundamental natural period (Ta)of the buildings

$\mathrm{Ta}=0.075 \mathrm{~h} 0.75$ Moment resisting RC frame building without brick infill wall

$\mathrm{Ta}=0.085 \mathrm{~h} 0.75$ Moment resisting steel frame building without brick infill walls

Where,

$\mathrm{h}$-is the height of building in $\mathrm{m}$

$\mathrm{d}$ - is the base of building at plinth level in $\mathrm{m}$, along the considered direction of

lateral force.

(ii) Determination of base shear (VB) of the building $\mathrm{VB}=\mathrm{Ah} \times \mathrm{W}$

Is the design horizontal seismic coefficient, which depends on the seismiczone factor (Z), importance factor (I), response reduction factor $(\mathrm{R})$ and the average response acceleration coefficients $(\mathrm{Sa} / \mathrm{g})$. Sa/g in turn depends on the nature of foundation soil (rock, medium or soft soil sites), natural period and the damping of the structure.

\subsection{RESPONSE SPECTRUM METHOD}

The response spectrum technique is really a simplified special case of modal analysis. The modes of vibration are determined in period and shape in the usual way and the maximum response magnitudes corresponding to each mode are found by reference to a response spectrum. The response spectrum method has the great virtues of speed and cheapness. There are two major disadvantages of using this approach. First, the method produces a large amount of output information that can require an enormous amount of computational effort to conduct all possible design checks as a function of time. Second, the analysis must be repeated for several different earthquake motions in order to 
assure that all the significant modes are excited, since a response spectrum for one earthquake, in a specified direction, is not a smooth function. According to the code, dynamic analysis may be performed using either response spectrum method or the time history method. In either method, the design base shear (VB) is compared with a base shear VB calculated using the fundamental period Ta. It suggests that when $\mathrm{VB}$ is less than $\mathrm{VB}$, all the response quantities (for example member forces, displacements, Storey force, Storey shears and base reactions) must be suitably scaled by multiplying with VB/VB. As per IS: 1893-2002 (PART 1) provisions, dynamic analysis shall be performed to obtain the design seismic force, and its distribution to different levels along the height of the building and to the various lateral load resisting elements, for the following buildings: (a) Regular buildings: Those greater than $40 \mathrm{~m}$ in height in Zones IV and V, and those greater than $90 \mathrm{~m}$ in height in Zones II and III. (b) Irregular buildings: All framed buildings higher than $12 \mathrm{~m}$ in Zones IV and V, and those greater than $40 \mathrm{~m}$ in height in Zones II and III.

\section{LOADINGS}

This stage involves determination of various types that are acting on the structures. The values of types of loads are taken from the relevant IS-codes.

\section{TYPES OF LOADS:}

Various types of loads on a structure and requiring consideration in design are

\section{DEAD LOAD:}

This is the permanent of stationary load like selfweight of structural elements. This includes

a)self-weight b)weight of finished c)weights of partitions walls etc.,

\section{LIVE LOAD: (AS PER IS-875-Part-2)}

These are non-permanent or moving loads. This type of load includes the following. Imposed loads (fixed) weight of fixed beams in auditoriums. Fixed machinery, partition walls. These loads though, fixed in positions cannot relied up on to act permanently throughout the life of the structure. Imposed loads (not fixed) these loads can change either in magnitude or position very often such as traffic loads weight of furniture etc..,

\section{INTRODUCTION TO ETABS AND STAAD Pro}

\subsection{ETABS:}

ETABS is sophisticated software for analysis and design program developed specifically for buildings systems. ETABS version-2013.1.5 features an in intuitive and powerful graphical interface coupled with unmatched modeling, analytical, and design procedures, all integrated using common database. Although quick and easy for simple structures, ETABS can also handle the largest and most complex building models, including a wide range of nonlinear behaviors, making it the tool of choice for structural engineers in the building industry.

\subsubsection{MODELING FEATURES}

The ETABS building is idealized as an assemblage of area, line and point objects. Those objects are used to represent wall, floor, column, beam, brace and link / spring physical members. The basic frame geometry is defined with reference to a simple three dimensional grid system. With relatively simple modeling techniques, very complex framing situations may be considered. The building may be unsymmetrical and non-regulator in plan, Torsional behavior of the floors and understory compatibility of the floors are accurately reflected in the results. The solution enforces complete three-dimensional displacement compatibility, making it possible to 
capture tubular effects associated with the behavior of tall structures having relatively closely spaced columns. Semi-rigid floor diaphragms may be modeled to capture the effects of in plane floor deformations. Floor objective may span between adjacent levels to create sloped floors (ramps), which can be useful for modeling parking garage structures.

\subsubsection{ANALYSIS FEATURES}

Static analysis for user specified vertical and lateral floor on story loads are possible. If floor elements with plate bending capability are modeled, vertical uniform loads on the floor are transferred to the beams and columns through bending of the floor elements.

The program can automatically generate lateral wind and seismic load patterns to meet the requirements of various building codes. Three dimensional mode shapes and frequencies, model participation factors, direction factors and participating mass percentage are evaluated using Eigen vector or Ritz-vector analysis-Delta analysis effects may be included with static or dynamic analysis. Response spectrum analysis, linear time history analysis, nonlinear analysis and static nonlinear analysis are possible. The static nonlinear capabilities also allow you to perform incremental construction analysis, so that forces that arise as a result of construction sequence are included. Results from the various static load cases may be combined with each other or with the results from the dynamic response dynamic response spectrum or time history method. Output may be viewed graphically, displayed in tabular output, the types of output include reactions, member forces, mode shapes, participation factors, static and dynamic story displacements and story shears inter story drifts and joint displacements, time history traces and more.

\subsection{STAAD Pro}

STAAD Pro allows structural engineers to analyze and design virtually any type of structure through its flexible modeling environment, advanced features and fluent data collaboration. Flexible modeling is provided by a state-of-the-art graphical environment and the design supports over 70 international codes and over 20 U.S. codes in 7 languages. An array of advanced structural analysis and design features are included such as time history and push over analysis and cable (linear and non-linear) analysis. Efficiencies are gained through the ability to maintain and streamline current workflows with fluent data collaboration. STAAD.Pro integrates with other Bentley products such as STAAD.foundation and ProSteel and Open STAAD is provided for integration with third party programs. Increased client base and therefore business growth can be realized in using STAAD.Pro to serve a broad spectrum of structural design projects and a global market. Staad is powerful design software licensed by Bentley Staad stands for structural analysis and design Any object which is stable under a given loading can be considered as structure. So first find the outline of the structure, where as analysis is the estimation of what are the type of loads that acts on the beam and calculation of shear force and bending moment comes under analysis stage. Design phase is designing the type of materials and its dimensions to resist the load. This we do after the analysis. To calculate s.f.d and b.m.d of a complex loading beam it takes about an hour. So when it comes into the building with several members it will take a week. Staad pro is a very powerful tool which does this job in just an hour's staad is a best alternative for high rise buildings. Now a day's most of the high rise buildings are designed by staad which makes a compulsion for a civil engineer to know about this software. 


\section{ANALYSIS AND DESIGN OF G +12 BUILDING USING STAAD. Pro}

Step - 1 : Creation of nodal points.

Based on the column positioning of plan we entered the node points into the STAAD file

Step - 2 : Representation of beams and columns.

By using add beam command we had drawn the beams and columns between the corresponding node points.

Step - 3: 3D view of structure.

Here we have used the Transitional repeat command in $\mathrm{Y}$ direction to get the 3D view of structure.

Step - 4: Supports and property assigning.

After the creation of structure the supports at the base of structure are specified as fixed. Also the materials were specified and cross section of beams and columns members was assigned.

Step - 5: 3D rendering view.

After assigning the property the $3 \mathrm{~d}$ rendering view of the structure can be shown.

Step - 6: Assigning of seismic loads.

In order to assign Seismic loads firstly we have defined the seismic loads according to the code IS 1893:2002 with proper floor weights. Loads are added in load case details in $+X,-X,+Z,-Z$ directions with specified seismic factor.

Step - 7: Assigning of wind loads.

Wind loads are defined as per IS 875 PART 3 based on intensity calculated and exposure factor. Then loads are added in load case details in $+\mathrm{X},-\mathrm{X},+\mathrm{Z},-\mathrm{Z}$ directions.

Step - 8: Assigning of dead loads.

Dead loads are calculated as per IS 875 PART 1 for external walls, internal walls, parapet wall including self-weight of structure.

Step - 9: Assigning of live loads.

Live loads are assigned for every floor as $4 \mathrm{kN} / \mathrm{m} 2$ based on IS 875 PART 2.
Step - 10: Adding of load combinations.

After assigning all the loads, the load combinations are given with suitable factor of safety as per IS $\mathbf{8 7 5}$ PART 5.

Step - 11: Analysis.

After the completion of all the above steps we have performed the analysis and checked for errors.

Step - 12: Design.

Finally concrete design is performed as per IS 456: 2000 by defining suitable design commands for different structural components. After the assigning of commands again we performed analysis for any errors.

\section{ANALYSIS AND DESIGN OF G + 12 BUILDING USING ETABS}

Step - 1: Step by Step procedure for ETABS Analysis. The procedure carried out for Modeling and analyzing the structure involves the following flow chart.

Step - 2: Creation of Grid points \& Generation of structure. After getting opened with ETABS we select a new model and a window appears where we

had entered the grid dimensions and story dimensions of our building. Here itself we had generated our 3D structure by specifying the building details in the following window.

Step - 3: Defining of property. Here we had first defined the material property by selecting define menu material properties. We add new material for our structural components (beams, columns, slabs) by giving the specified details in defining. After that we define section size by selecting frame sections as shown below $\&$ added the required section for beams, columns etc.

Step - 4: Assigning of Property

After defining the property we draw the structural components using command menu. Draw line for 
beam for beams and create columns in region for columns by which property assigning is completed for beams and columns.

Step - 5: Assigning of Supports. By keeping the selection at the base of the structure and selecting all the columns we assigned supports by going to assign menu joint $($ frame. Restraints (supports)fixed.

Step - 6: Defining of loads

In STAAD program we define only seismic and wind loads whereas in ETABS all the load considerations are first defined and then assigned. The loads in ETABS are defined as using static load cases command in define menu

Step - 7: Assigning of Dead loads

After defining all the loads dead loads are assigned for external walls, internal walls.

Step - 8: Assigning of Live loads

Live loads are assigned for the entire structure including floor finishing.

Step - 9: Assigning of wind loads

Wind loads are defined and assigned as per IS 875 1987 PART 3 by giving wind speed and wind angle in $\mathrm{X}, \mathrm{X} 1, \mathrm{Z}$ \& $\mathrm{Z} 1$ directions as $0,180,90,270$ respectively.

Step - 10: Assigning of Seismic loads. Seismic loads are defined and assigned as per IS 1893: 2002 by giving zone, soil type, and response reduction factor in $\mathrm{X}$ and $\mathrm{Y}$ directions.

Step - 11: Assigning of load combinations. Load combinations are given as mentioned in STAAD. Pro based on IS 8751987 PART 5 using load combinations command in define menu

Step - 12: Analysis, after the completion of all the above steps we have performed the analysis

and checked for errors.

Step - 13: Design

After the completion of analysis we had performed concrete design on the structure as per IS 456:2000. For this go to Design menu concrete design select design combo. After this again go to design Menu concrete frame design start design \ check of structure then ETABS performs the design for every structural element.

\section{VII.ETABS MODELLING}

\section{DEFINE GEOMETRY:}

The Building Plan Grid System and Storey Data form is used to specify horizontal and vertical grid line spacing, storey data, storey elevation and units. They automatically add the structural objects with appropriate properties to the model.

\section{RESPONSE SPECTRUM FUNCTIONS}

Response spectrum functions are pseudo spectral acceleration versus period functions for use in response spectrum analysis. In this program the acceleration values to be normalized; that is, the functions themselves are not assumed to have units. Instead, the units are associated with a scale factor that multiplies the function and is specified when we define the response spectrum case.

\section{STATIC LOAD CASES:}

Loads represent the actions upon the structure, such as force, pressure, support displacement, thermal effects and others. A spatial distribution of loads upon the structure is called static load case. Define as many load cases as needed. Typically separate load case definitions would be used for dead load, live load, static earthquake load, wind load, snow load, and Thermal load.

\section{CONCLUSION}

Actually the results of analysis should match with the classical analysis solutions, whatever the type of analysis we do using whatever $\mathrm{S} / \mathrm{W}$ package. The finer thing that we should note in all these packages is that, there are parameters/properties such as 
boundary conditions, material properties etc., which are applied to the generated model by the software package by default at the initial stage. By the analysis results, we can find that the base reactions for the dead load of whole structure is coming little bit different from all the software's. Besides this, we can find base reactions for the live load of the building are equal through both the software's. Furthermore, the bending moment and shear force are also coming nearly same for the considered sample column by all the structural software's.

\section{REFERENCES}

[1]. Giordano, M. Guadagnuolo and G. Faella "Pushover Analysis of Plan Irregular Masonry Buildings" The 14th World Conference on Earthquake Engineering October 12-17, 2008, Beijing, China.

[2]. Prof. K S Sable, Er. V A Ghodechor, Prof. S B Kandekar "Comparative Study of Seismic Behavior of Multistory Flat Slab and Conventional reinforced Concrete Framed Structures".

[3]. Belejo, R. Bento \& C. Bhatt "Comparison of different computer programs to predict the seismic performance of SPEAR building by means of Pushover Analysis the SPEAR building by means of Pushover Analysis" Instituto Superior Técnico, Lisbon, Portugal

[4]. "Displacement Based Design of Vertically Irregular Framewall Structures" - Rose School Thesis Work By Suhaib Salawdeh

[5]. "Performance Based Seismic Design and Assessment of Irregular Steel Structures R. Peres, R.Bento IST, Technical University of Lisbon, Portugal J. M. Castro Faculty of Engineering, University of Porto, Portugal.

[6]. "Seismic design of vertically irregular reinforced concrete structures" - Thesis work submitted by Satrajit Das
[7]. McCrum Lunch "Seismic Analysis of Braced Plan Irregular Structures Using Hybrid Testing Daniel" lecture at the Department of Civil, structural \& Environmental Engineering, Trinity College Dublin on 30th November 2011

[8]. Shaikh Abdul Aijaj Abdul Rahman, Girish Deshmukh "Seismic Response of Vertically Irregular RC Frame with Stiffness Irregularity at Fourth Floor" ISSN 2250-2459, ISO 9001:2008 Certified Journal, Volume 3, Issue 8, August 2013

\section{Cite this article as :}

K. Harshavardhana Reddy, D. Mohammed Rafi, Dr. C. Ramachandrudu, "Comparative Study on The Analysis Results of Multi-Storeyed Commercial Building $(\mathrm{G}+12)$ by Using Staad.Pro and ETABS", International Journal of Scientific Research in Science and Technology (IJSRST), Online ISSN : 2395-602X, Print ISSN : 2395-6011, Volume 6 Issue 3, pp. 248-254, May-June 2019. Available at doi : https://doi.org/10.32628/IJSRST196344 Journal URL : http://ijsrst.com/IJSRST196344 